\title{
Naturaleza y sentido del trabajo del maestro y la maestra en el siglo XXI Anotaciones para contribuir al debate sobre el estatuto docente ${ }^{1}$
}

\author{
NATURE AND MEANING OF WORK OF THE TEACHER AND THE TEACHER IN THE XXI CENTURY \\ ANNOTATIONS TO CONTRIBUTE TO THE DEBATE ON TEACHER STATUS \\ NATUREZA E SIGNIFICADO DO TRABALHO DO PROFESSOR E DO PROFESSOR NO SÉCULO XXI \\ ANOTAÇÕES DE CONTRIBUIR PARA O DEBATE SOBRE O ESTATUTO DE PROFESSOR
}

Marco Raúl Mejía J. / marcoraulm@gmail.com

\section{Resumen}

En este texto abordaremos en un primer momento esas transformaciones y la manera como ellas reorganizan el control del capital en la sociedad y de manera específica en la educación. Luego abordaremos el lugar del maestro y la maestra en esa reconfiguración, así como el tipo de trabajo que realiza, cómo es también reorganizado en los tiempos que corren. En un tercer momento, buscaremos dar cuenta de algunos asuntos que son consustanciales al trabajo del maestro y la maestra y la manera como han abierto a comprensiones variadas y transforman miradas del pasado sobre ellos, modificando aspectos centrales en el trabajo de los educadores. Allí nos encontramos con aspectos como un nuevo estatuto epistemológico, contextual, científico y ético, lo que implica construir su quehacer con sentido para estos tiempos, lo cual da numerosas pistas para un estatuto que dé cuenta de ellos y permita construir nuevos horizontes políticos y gremiales, así como político-pedagógicos. Terminaremos planteando lo que implica lo enunciado para la profesión de maestra y maestro en estos tiempos, desarrollando unas tensiones que están a la base de una discusión por construir apuestas de un docente que se instala en el siglo XXI.

\section{Summary}

In this paper board at first these changes and how they reorganize control of capital in society and specifically in education. Then board the place of the teacher and the teacher in this reconfiguration, and the type of work you do, how it is also reorganized the times. In a third time, we will seek to account for some issues that are inherent in the work of the teacher and the teacher and the way opened to various understandings of the past and transform looks upon them by modifying key aspects in the work of educators. We met aspects as a new epistemological status, contextual, scientific and ethical, implying build their work meaningful for these times, which gives many clues to a statute that realize them and allow to build new political horizons and trade as well as political-pedagogical. Finish raising implying the statement for the teaching profession and teacher in these times, developing tensions that are the basis of a discussion bets build a teaching that is installed in the XXI century.

\section{Resumo}

Neste quadro de papel no primeiro essas mudanças e como elas reorganizar controle do capital na sociedade e especificamente na educação. Em seguida, embarcar no lugar do professor e do professor nesta reconfiguração, e do tipo de trabalho que você faz, como ele também é reorganizado os tempos. Em um terceiro momento, procuraremos dar conta de alguns problemas que são inerentes ao trabalho do professor e do professor e da forma como abriu a vários entendimentos do passado e transformar olhares sobre eles, modificando aspectos-chave no trabalho de educadores. Nós nos encontramos aspectos como um novo estatuto epistemológico, contextual, científica e ética, o que implica construir seu trabalho significativo para estes tempos, o que dá muitas pistas sobre um estatuto que lhes permitem perceber e construir novos horizontes políticos e comércio bem como político-pedagógico. Levantamento Finish implicando a declaração para a profissão docente e professor nestes tempos, desenvolvendo tensões que são a base de uma discussão apostas construir um ensino que está instalado no século XXI.

\author{
Palabras clave \\ Control capital, sociedad, \\ cambio de época, busqueda \\ critica, trabajo inmaterial, \\ asalariado, trabajador de la \\ cultura.
}

\section{Key words}

Control capital, society, changing times, search criticizes, immaterial labor, wage, cultural worker.

\section{Palavras chave}

Controle de capital, a sociedade, a mudança dos tempos, busca critica, trabalho imaterial, salário, trabalhador cultural.

1 Este texto hace parte de un documento más amplio, que constituirá mi próximo libro a publicarse en la Editorial Desde Abajo: Las escuelas del capitalismo, espacio polisémico en disputa - Tomo III. 
Al despolitizar la educación y reducirla al terreno de las destrezas, la ideología y la política liberales terminan por generar una práctica educativa que contradice u obstaculiza una de las exigencias fundamentales del mismo avance tecnológico, la de preparar a sujetos críticos, capaces de responder con presteza y eficacia a desafíos inesperados y diversificados. En realidad, el entrenamiento estricto tecnicista habilita al educando para repetir determinados comportamientos. Sin embargo, estamos algo más que esto. Necesitamos un saber técnico real, con el que responder a los desafíos tecnológicos, un saber que se sabe componiendo un universo mayor de saberes. Saber que no censura las preguntas legítimas que se hagan en torno a él: en beneficio de qué o de quién; contra qué o contra quién se utiliza. Saber que no se reconoce indiferente a la ética y a la política, pero no a la ética del mercado ni a la política de esta ética.

\section{Paulo Freire 1}

Esta cita del latinoamericano universal en educación y pedagogía, quien vislumbra las implicaciones de los nuevos procesos en marca de la tecnología para el pensamiento crítico y emancipador, me sirven para darle entrada en este texto a los entendimientos del trabajo inmaterial, los cuales reformulan las maneras del trabajo y en forma específica las del trabajo de maestros y maestras de estos tiempos.

Un asunto central a las discusiones actuales por el Estatuto docente de los maestros y maestras colombianas es abordar el debate sobre la naturaleza y el tipo de trabajo que realizan, ya que de ello se van a derivar asuntos sobre los cuales deben versar las propuestas de Estatuto y sus correlatos reivindicativos, que incidirán en reconstruir las organizaciones de cara a este nuevo siglo a la luz de la revolución científico-técnica en marcha y la manera como el capital se las ha apropiado y reestructurado su proyecto de control.

1 FREIRE, Paulo. Pedagogía de la Indignación. Madrid. Ediciones Morata. 2001. Páginas 136-137.
Se ha discutido desde finales del siglo XIX y a lo largo del $X X$, qué tipo de trabajo realiza un maestro en la sociedad: iproductivo?, ¿reproductivo?, ¿genera plusvalía2? O es alguien que es necesario al proceso de producción y la valorización sin producirla. En ese sentido, ¿quién es un trabajador?, y iquién un trabajador de la cultura? ¿Un profesional?, ¿un trabajador proletarizado?, o ¿un trabajador proletarizado de la enseñanza y el conocimiento?, ¿un funcionario público?, o según la más remota denominación en sus orígenes: una vocación o un segundo padre o madre.

De lo que determinemos que es, es decir, del lugar de él o ella en la sociedad actual y de su relación con los otros trabajos depende el marco de lucha que se construya para hacer posible el reconocimiento de maestras y maestros, en las condiciones de una sociedad que se recompone a la luz de las nuevas transformaciones en el conocimiento, la tecnología, la información, los nuevos lenguajes, la comunicación, la innovación y la investigación, no solo en el lugar que el sistema le da a ello, sino ante todo en las lecturas críticas, la importancia que se le otorga como una de las profesiones centrales a la constitución del trabajo inmaterial de estos tiempos.

Para ello en este texto abordaremos en un primer momento esas transformaciones y la manera como ellas reorganizan el control del capital en la sociedad y de manera específica en la educación. Luego abordaremos el lugar del maestro y la maestra en esa reconfiguración, así como el tipo de trabajo que realiza, cómo es también reorganizado en los tiempos que corren.

En un tercer momento, buscaremos dar cuenta de algunos asuntos que son consustanciales al trabajo del maestro y la maestra y la manera como han abierto a comprensiones variadas y transforman miradas del pasado sobre ellos, modificando aspectos centrales en el trabajo de los educadores. Allí nos encontramos con aspectos como un nuevo estatuto epistemológico, contextual, científico y ético, lo que implica construir su quehacer con sentido para estos tiempos, lo cual da numerosas pistas para un estatuto que dé cuenta de

2 Recordemos que Marx había señalado que en algunos trabajos la producción y el consumo son simultáneos: por ejemplo, en actores, profesores, médicos, padres (sacerdotes). 
ellos y permita construir nuevos horizontes políticos y gremiales, así como político-pedagógicos.

Terminaremos planteando lo que implica lo enunciado para la profesión de maestra y maestro en estos tiempos, desarrollando unas tensiones que están a la base de una discusión por construir apuestas de un docente que se instala en el siglo XXI, con la perspectiva de construir una escuela, una educación, y a sí misma(o) como campos en disputa con y desde un proyecto emancipador y transformador de la sociedad, haciendo real en su cotidiano vivir, el planteamiento de que otro mundo es posible, y la construcción de él reconociéndose como un luchador que hace contrahegemonía en uno de los espacios centrales de la hegemonía y las diferentes dinámicas y procesos de él.

Comprender las nuevas formas del control del capital y sus manifestaciones en la sociedad y la educación en este cambio de época ${ }^{3}$

La crisis que vivió el capitalismo en la década de los 70 del siglo anterior, no sólo tenía que ver con la entrada de un nuevo sector hegemónico en su proyecto de control y poder. El capital financiero, el cual desplazaba al manufacturero, ante las dificultades de pago de los préstamos realizados a muchas de las economías emergentes generó una crisis en la cual uno de los lugares más visibles de ella fue la deuda externa. También, como otro factor adicional, el mundo se encontraba ante unas modificaciones estructurales, las cuales emergieron como nuevas realidades en donde el conocimiento, la tecnología, la información, la comunicación, los nuevos lenguajes, la innovación y la investigación, constituían núcleos emergentes en la sociedad generando sectores que dinamizaban la producción de vida y sus bienes materiales y simbólicos, restructurando relaciones en sus diferentes ámbitos culturales, económicos, políticos, y sociales, produciendo un fenómeno de "cientifización" de los procesos de producción.

3 Este primer numeral son apartes del texto de mi autoría "Construir la teoría crítica del trabajo inmaterial y las NTIC, una aproximación desde la educación popular", publicado en:
Ciencia y tecnología no sólo se manifiestan en la vida cotidiana transformando los entornos locales, sino que se convierten en fuerzas productivas materiales, en donde ellas son utilizadas como un empleado más, un miembro del obrero colectivo del capital social, gestando una nueva producción de plusvalía a nivel mundial, dando lugar al mayor desarrollo del trabajo inmaterial. Los trabajadores de esta nueva economía se convierten en portadores de su medio de trabajo: el conocimiento reorganizando no sólo la producción sino las relaciones sociales y sus dinámicas de poder, reasignando el papel de los sujetos en ello.

\section{La crisis de la década de los 70 del siglo pasado}

Es importante para comprender estas nuevas lógicas de control, la manera como se le da salida a la crisis vivida por el capitalismo en la segunda mitad del siglo XX, ésta se realizó en parte mediante la apropiación por parte del capital, de los nuevos sistemas de la ciencia, la tecnología y la innovación a través de un control directo de las Nuevas Tecnologías de la Información, el Conocimiento y la Comunicación (NTIC). 4 Allí fueron canalizados parte de los capitales que en medio de la crisis requerían mantener su tasa de ganancia y que en ese momento no encontraban dónde ser colocados. Esto llevó a inversiones masivas y a un fuerte crecimiento de éstos que entraron a dinamizar los procesos gestados en la microelectrónica, erigiéndose las NTIC no sólo en un nuevo componente de la dinámica de la sociedad capitalista de este tiempo, sino de las nuevas formas de control y acumulación de él.

Es tan potente y visible esta dinámica en la reorientación de la sociedad actual, que se le asignan diferentes nombres, configurando una especie de sentido común sobre la época que expresaba las nuevas formas cómo se producían y visualizaban los nuevos tiempos y espacios en donde se organizaba el capitalismo, sus

\footnotetext{
4 Recordemos cómo algunos autores del marxismo, ven el desarrollo de éstas como el resultado de las luchas sociales y obreras de los siglos XIX y XX por la dignificación y contra la penuria del trabajo material, sólo que el momento en el cual se da su mayor desarrollo (crisis del socialismo real), no existen condiciones de poder en la sociedad para colocarlas al servicio de los movimientos y los grupos anticapitalistas. De igual manera, son nuevas porque son las propias del entorno cultural presente, diferentes a las específicas de otros tiempos y momentos históricos.
} 
mecanismos de producción de la vida, sus significantes socialmente intercambiables. Es decir, los modos y medios de producción del conocimiento-poder, en donde nuevamente son expresados bajo la forma de dominio y control en manos de una élite encargada de gestar y monopolizar los nuevos lenguajes y los sentidos de la vida de las personas en función de la maximización de la ganancia y la producción de mercancías.

Es en este marco que se produce una reestructuración de la producción y los negocios. El sector financiero invierte en los nuevos sistemas del conocimiento, la tecnología, la información, la comunicación, los nuevos lenguajes, la innovación y la investigación, que se hacen estratégicos a raíz de su uso en la vida cotidiana, y el desarrollo y cambio permanente de ellos y por consiguiente de un crecimiento con características transnacionales, lo cual les permite colocar su capital a salvo yendo más allá de los mercados internos, en unas nuevas formas de industrias ligadas a estos procesos tecnológicos y comunicativos, en donde también se reestructuran los consumos.

Es en el aprovechamiento de los tiempos de la crisis y los nuevos lugares de inversión lo que permite convertir en estratégicas a las industrias que dan forma a las NTIC, produciendo una reestructuración de la producción de la sociedad y de las maneras de organización y control del capital. Un informe del New York Times del 2008, muestra cómo a finales de las década de los 80 del siglo pasado, las NTIC y los programas de informática representaban no menos de la mitad de las inversiones realizadas por las multinacionales, Ilegando a un billón 750.000 millones de dólares, y cómo ese mismo año de la publicación, que es el de la crisis financiera mundial (por las hipotecas de vivienda), su inversión aumentó $23 \%$ y el tráfico en la red $55 \%$ en el 2008 y proyectada 74\% en el 2009 (Ramonet, 1997).

Una de las mayores dificultades se encuentra en comprender en clave de teoría crítica y desde los acumulados de ella ${ }^{5}$, el tiempo que vivimos, los procesos de reproducción material y social donde la realidad se ha transformado a pasos acelerados, las nuevas fuentes de productividad centrados en el conocimiento, la tecnología la información y la comunicación nos colocan frente a un modelo productivo con características particulares y sobre nuevas bases materiales y sociales. Ahí, según Rifkin (2000), la riqueza hoy no se soporta sobre las mismas bases que en el pasado, sino en la imaginación y la creatividad transformando también las subjetividades, lo cual para las teorías del post-marxismo hace necesario reconocer las características de esas nuevas formas de acumulación, en donde el conocimiento y el trabajo intelectual ya no se presentan ni se autorrealizan como actividad útil, sino como relación salarial directa e indirecta, exigiendo la construcción y ampliación de la teoría política del valor para estas nuevas formas de acumulación.

\section{Comprendiendo las modificaciones del capital}

No cambia la esencia contradictoria del modo capitalista de producción (monopolización, incremento de la tasa de ganancia, velocidad en los ciclos de realización de la ganancia, apropiación privada de ella, explotación), pero si cambian sus formas de realización de ellas y las formas de control y poder en ellas, emerge un trabajo inmaterial que es parte del proceso de trabajo, el cual pertenece al sujeto productor. Algunos autores ven acá la modificación del trabajo abstracto marxista, lo que transforma la manera de producir subjetividad en la generalización de ese trabajo, este que acorta los ciclos del capital fijo.

Algunos autores (Virno, 2003) ven una reactualización de "la inteligencia general" trabajada por Marx en los Grundisse, en donde las transformaciones producidas por la gran industria al comienzo se hacen desde el trabajador, quien anima con su saber hacer, con su habilidad, los instrumentos para efectuar la transformación de las materias primas. Sin embargo, el maquinismo va dejando atrás el instrumento del trabajador individual y la actividad productiva se manifiesta como actividad de la máquina convirtiéndose en una "unidad virtuosa" que posee en ese momento la fuerza y la habilidad que antes era del obrero.

5 Las páginas siguientes del texto retoman elementos de: Los movimientos educativos y pedagógicos del siglo XXI, en: Revista Internacional de Filosofía. No.58. 2010 y en: Revista Ciencia Política, No. 11, 2011.

8 nodos y nudos / volumen 4 N.o 37 / julio - diciembre / 2014 ISSN: 0122-4328 / p.p 05-20 / 


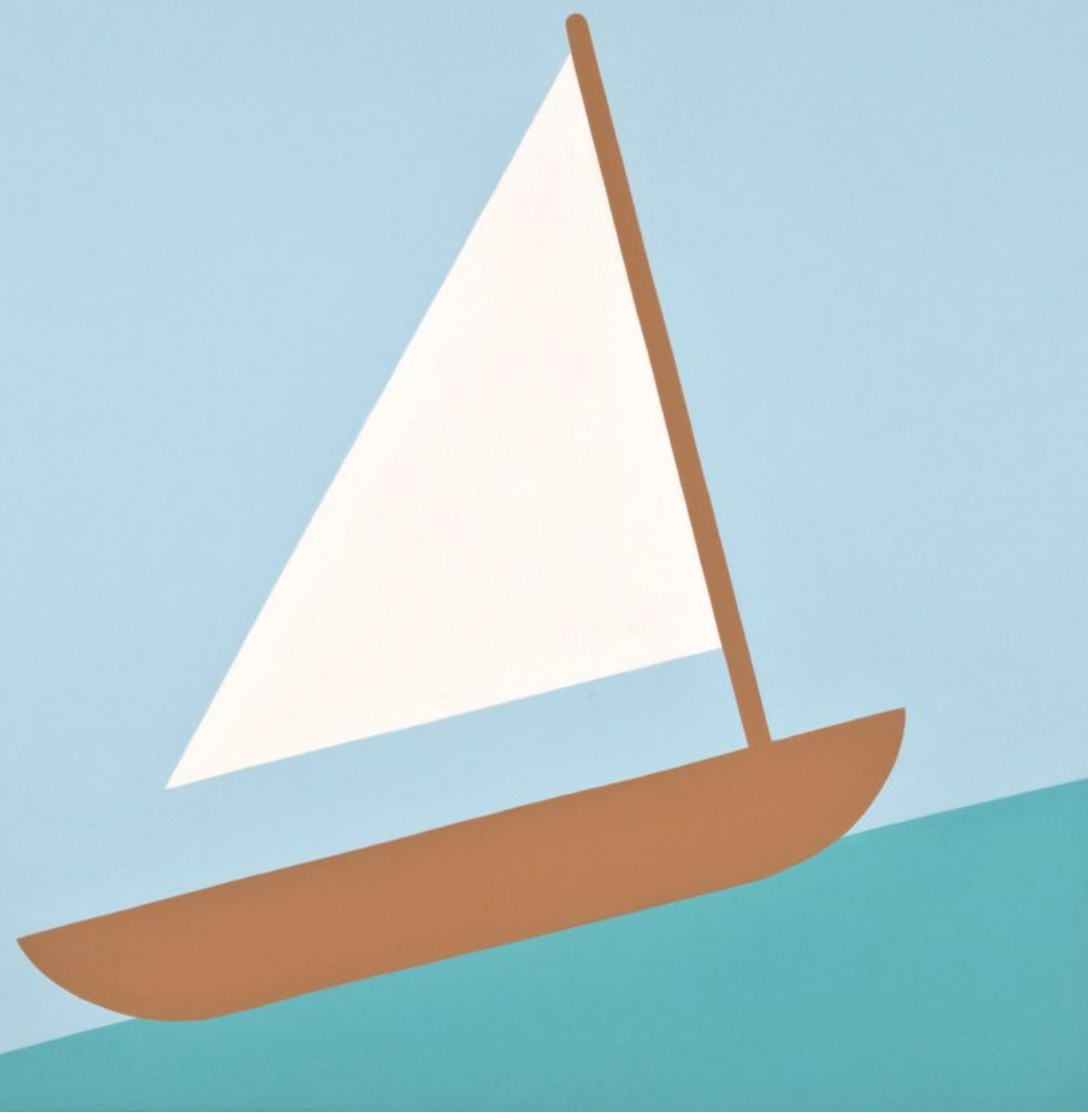

Franklin Aguirre ॥ Título: Autorretrato ॥ Técnica: Acrílico sobre lienzo ॥ Tamaño: 100 X 100 cm ॥ Año: 2006 
Esto da inicio a la sumisión real del trabajo al capital que continuará en las fases sucesivas del capitalismo con las siguientes características:

- El proceso de producción deja de ser un lugar en el cual la unidad dominante es el trabajo.

- El trabajo objetivado deja de ser un simple producto que sirve de instrumento para erigirse como la fuerza productiva misma.

- El resultado del trabajo social general se fija en el capital y no en el trabajo.

- La ciencia se manifiesta en las máquinas y el proceso de producción se convierte por ello en aplicación tecnológica de la ciencia.

- El trabajo inmediato y su cantidad deja de ser el elemento determinante de la producción.

- La producción del valor se desprende y deja de estar centrada en el trabajo inmediato.

- El sobretrabajo deja de ser el fundamento de la riqueza y la explotación.

La ciencia va a ser ese intelecto general que Marx ve materializado en el sistema de máquinas, convertida en una nueva fuente de riquezas y razón de que el conocimiento, la tecnología y sus variadas versiones de desarrollo científico se convierten en fuerza productiva inmediata y del colectivo social humano apropiada por el capital sin devolverle nada a la sociedad. Se ha logrado una incorporación de la inteligencia generada al capital.

Estos procesos son visibles en los desarrollos de la informática, la automatización, las cuales transforman las relaciones de los individuos con las máquinas, con lo cual según Virno, a quien sigo: redujo los tiempos "muertos", se automatizó la integración (fabricación asistida por computadores), lo cual da paso a la polivalencia con su multifuncionalidad y planes flexibles, apareciendo una fuerza laboral movible, precaria, interina, subcontratada, con división de la cadena productiva generando grupos semiautónomos y polivalentes.

La inteligencia general se convierte en una realidad en los sujetos mismos al darse esa nueva forma del trabajo vivo que es el trabajo inmaterial, el cual da contenido preciso a la organización productiva de este tiempo, centrada en la ciencia, configurando un nuevo tipo de trabajo que ya no tiene su soporte principal en la materia prima, sino sobre el conocimiento, la información, la innovación, que ha de recibir ésta para que funcione el nuevo sistema de máquinas y tecnológico en lo que ha sido denominado "la nueva geografía del trabajo" (Sassen, 2001).

Estos cambios se manifiestan en la salida de ciertos capitales individuales y estatales a niveles geoestratégicos. La dilatación de una esfera de la producción hacia la del consumo, un ataque directo al salario por vía de la desprotección sindical, ausencia de trabajo humano por vía de la tecnología en múltiples actividades ligadas al ciclo productivo (Offe, 1992).

Esta dinámica se acompaña de una fragmentación de la producción en forma de descentralización productiva, externalización, sub-contratación, produciendo una disolución de la clase obrera clásica y un quiebre de las organizaciones en cuanto la excesiva temporalidad y las nuevas condiciones de los asalariados produce una reestructuración de la organización clásica de los trabajadores, los cuales al no entender porque no se les da respuesta en sus nuevas condiciones, generando una caída de afiliación y una reducción de las bases sociales (Tronti, 1999).

Además, con dos zonas contrapuestas en esa organización social del trabajo en la sociedad, una vulnerable con producción precaria y de trabajo simple en la nueva organización social del trabajo "por ejemplo, algunas de las maquilas"y otra de innovación y alto dinamismo en el conocimiento y la tecnología a la cual quedan adscritos los procesos educativos y de la cual salen y entran según los resultados que vayan entregando en la producción material de la sociedad, abriendo una disputa de alta producción de valor a partir de la ciencia con características bastante nuevas comparadas con la forma de producción anterior.

Como vemos, estamos en un momento de reinterpretación, en donde los mapas contextuales de acción de mediación con los cuales nos movíamos en el pasado, no son suficientes para estas nuevas realidades, lo cual va a exigir actualizar los fundamentos conceptuales, no sólo de la forma que toma en estos tiempos el cambio y las transformaciones civilizatorias generadas en el proceso de revolución científico-técnica en marcha, sino también de las bases de la teoría crítica para que pueda dar cuenta 
de este cambio de época en clave de nuevo proyecto de poder y de control, lo cual ha generado desde esta apuesta interpeladora, una serie de búsquedas por interpretar esas modificaciones de este presente histórico, y construir los nuevos escenarios de emancipación.

Alimentando estas perspectivas críticas, algunas posiciones construyen una mirada en la cual el trabajo intelectual, se ha convertido en relación salarial directa o indirecta, aparece en una reificación del conocimiento-poder, en donde esa forma inmaterial del trabajo como mercancía se visibiliza y sufre una desvalorización social.

Al entrar esta nueva subjetividad que se constituye socialmente en esa relación salarial establecida desde el trabajo inmaterial, lo anterior genera una dinámica diferente de control de los mecanismos de producción de significantes, socialmente intercambiables. Esto muestra a un grupo reducido que se erige como gestor del monopolio de sentidos y significantes, lo cual se hace posible desde esos nuevos controles comunicativos y del lenguaje, que al ser colocados en el mercado en función de la maximización de las ganancias (rentabilidad) establecen otras características para el poder y sus formas de control.

Esta mirada ha llevado a algunos autores a hablar de tecnologías "duras" y tecnologías "blandas", más allá de los procesos que hacen su asimilación a ciencias "duras" y ciencias "blandas". Desde esta lectura crítica, las primeras estarían referidas a aparatos y bienes tangibles, estructuras físicas, maquinarias, y las segundas a esas formas inmateriales, no tangibles que circulan a través de los procesos, los conocimientos, las estructuras organizativas, procedimentales. Se afirma que en la educación todo el proceso de enseñanza-aprendizaje es "blando".

\section{La búsqueda crítica con el trabajo inmaterial y sus formas}

Esta separación complementaria de los diferentes trabajos, abre también otra perspectiva crítica en cuanto se comienza a hacer una lectura en la cual se muestra cómo parte del control sobre las personas se da a través de lograr que realicen sólo un uso instrumental de los aparatos desarrollados a partir de las tecnologías blandas, garantizando el control del poder en los procesos de tecnología blanda a través de mecanismos de propiedad intelectual y de patentes ${ }^{6}$.

Es acá donde un trabajo investigativo y educativo crítico permite romper esa separación y construir los nexos entre uno y otro proceso como producción humana reintegrando la unidad entre trabajo manual y trabajo intelectual, rompiendo así el nuevo fetiche sobre estas dinámicas nuevas en la sociedad, que organiza el capital sobre un uso instrumental intensivo. La ruptura que hizo el capital sobre trabajo manual e intelectual se reintegra en la relaboración de la inteligencia general a partir de esta nueva mirada para comprender esta producción como inseparable, lo cual también permite ampliar la idea de tecnología y verla en la producción campesina, en el conocimiento ancestral de nuestras comunidades originarias sobre el agua, los bosques, los cultivos, entre otros, lo cual hace del territorio ese lugar de contradicciones y conflictos en donde se constituye la acción humana en este tiempo, y que ha dado forma a lo que algunos autores han Ilamado "epistemologías del sur" (Santos, 2009).

Por ello, desde esta perspectiva, por ejemplo se hace central el control producido desde la investigación en todos los ámbitos, en cuanto esta se hace central a la constitución del capitalismo de estos tiempos, a la vez que se constituye a sí misma como campo de saber y conocimiento, estableciendo un espacio en disputa, pues se convierte en factor básico de la constitución de desigualdad y control en la sociedad actual7.

Sectores del pensamiento crítico ven en estos procesos la cuarta revolución industrial y tecnológica o "revolución de las redes informacionales". Allí se ubica el paradigma micro electrónico como una nueva realidad, lo cual exige incorporar lo informacional a la arquitec-

6 Un buen ejemplo de esa nueva complejidad interpretativa es el caso de Internet. Físicamente se ve en la relación de ella con la telefonía, pero ahí está también el software, que es el servicio, y más allá las redes sociales, constituyendo su contenido y mediaciones sociales. En ese sentido, es profundamente político.

7 PROGRAMA ONDAS de Colciencias. Informe de la reconstrucción colectiva del Programa Ondas - Búsquedas de la investigación como estrategia pedagógica. Período 2006-2008. Bogotá. Colciencias- Fundación FES-Programa Ondas. 2009. 
tura de las redes telemáticas y de comunicación, dando un salto cualitativo en las máquinas informaciones, constituyendo esas redes, las cuales intensifican los circuitos de reproducción del capital en las actividades de información, educación, investigación, desarrollo del sector servicios, en consultoría, información, comunicación, burocracia pública y privada, y en los servicios financieros. Ese cambio socio-técnico de este tiempo algunos lo han Ilamado "la cuarta edad de la máquina"8.

Asimismo, un autor como Jesús Martín-Barbero nos plantea que: "Nos enfrentamos así a otro cambio mucho más radical, consistente en los nuevos modos de producción del conocimiento y más específicamente a las nuevas relaciones entre lo sensible y lo inteligible. Ahí reside la lucidez de Castells, quien ata la mutación digital a la superación definitiva de la separación entre los dos lóbulos del cerebro: el de la razón argumental y el de la emoción pasional, ique por mera casualidad resulta ser el del arte! Pues bien, hoy día a lo que en las ciencias claves como la física y la biología se llama cada día más frecuentemente 'experimental', es a simular digitalmente en computador" (Martín Barbero, 2007).

Preguntarse por el lugar de los educadores populares y quienes trabajamos en esta perspectiva, así como de los diferentes actores críticos en este nuevo contexto, así como por el nudo de relaciones en las cuales queda inmerso su accionar, fruto de la manera como se construye este capitalismo que se reconfigura desde el conocimiento, la tecnología, la comunicación y la información, los nuevos lenguajes, la investigación y la innovación, significa preguntarse también por la manera como se transforman y crean los procesos críticos de este tiempo, así como en las diferentes maneras de entender la acción humana y lo educativo (Mejía, 2012).

También se dan modificaciones en la protesta, los movimientos sociales, lo gremial y lo político de este

8 ALVES, Giovanni. Trabalho e subjetividade. O espírito do toyotismo na era do capitalismo manipulatório. São Paulo. Boitempo. 2011. Este autor dice que la primera edad de la máquina es la producción de motores a vapor (1848); la segunda edad es la producción de motores eléctricos (1890); la tercera edad es la producción de máquinas electrónicas (1940); y la cuarta edad, es la producción de máquinas microelectrónicas informacionales, integradas a redes interactivas del ciberespacio (1980), generando una metamorfosis en las innovaciones tecnológicas y organizacionales, y también "sociometabólica", es decir, de las edades a través de la renovación generacional del trabajo vivo. tiempo, los cuales igualmente deben readecuarse y encontrar sus nuevas maneras de acción y comprensión de la realidad a la luz de estos nuevos fenómenos que lleven a transformar sus prácticas, surgiendo la tarea de desarrollar las nuevas conceptualizaciones en el sentido de las argumentaciones señaladas anteriormente, para dar forma a una ampliación de la teoría que a la vez que lea, ilumine a los nuevos procesos y caminos de lucha, recree la teoría para dar respuestas desde las propuestas de cambio y de emancipación al control de estos tiempos, encontrando las formas alternativas de esa emergencia de producción de significantes y de subjetividad desde una perspectiva crítica a la luz de los nuevos lugares del trabajo inmaterial.

Va a ser necesario un esfuerzo por construir las nuevas formas y las nuevas teorías de la acción humana, en coherencia con los desarrollos acumulados del pensamiento crítico que nos garanticen la fidelidad a los proyectos emancipadores, pero ello será un trabajo de construcción colectiva que genere una relación teóricopráctica de las resistencias de hoy que ya están presentes en múltiples lugares y se escriben desde las luchas iniciales de sus actores y desde el acumulado del pasado. En ese sentido, la Educación Popular, en su perspectiva de una propuesta para transformar la sociedad en la esfera de lo educativo propone también una construcción crítico-transformadora, para hacer una lectura de estas modificaciones societales para proponer y desarrollar los proyectos alternativos de este tiempo, en este caso, en la esfera de la educación formal.

\section{El maestro(a) como asalariado y trabajador de la cultura}

A nivel del trabajo de este tiempo, se hace más complejo y en el sentido de las palabras anteriores, su análisis requiere ser actualizado desde sus fundamentos. Lo anterior, dado que en esta etapa del capitalismo se consolida el sector servicios (Rubin, 1994) en la sociedad: esos trabajadores de oficina que tanto han servido a quienes se oponen a la interpretación marxista del trabajo y aun hablan de que no existe allí proletarización del empleo, y que lo que aparece son unas clases medias no proletarias, donde estarían los trabajadores de oficina, los funcionarios y algunos sostienen que allí 
estarían los maestros y maestras. Desde allí intentan construir una visión del maestro y la maestra que los saca de las luchas y de sus alianzas de clase. En ese sentido, son muchas de las concepciones que intentan convertirlos simplemente en unos profesionales funcionarios estatales; no en vano se desarrollan desde allí las propuestas de desprofesionalización y despedagogización, centrales al actual proceso.

Desde una visión marxista, Mandel (1997) lo define como un trabajo especializado, cuya producción y consumo coincide en que no está colocado en un producto material. Se señala que sus principales características serían:

- El trabajo materializado no toma forma de objeto vendible

- Lo vende el trabajador al capitalista, el cual lo vuelve mercancía en el mercado de bienes

- Es un trabajo y se produce bajo relaciones sociales capitalistas

Allí se da la discusión, en cuanto algunos dicen que es productivo, es decir, que produce plusvalía, es decir, añade valor al capital y contribuye al proceso de valorización del mismo (Braverman, 1984).

\section{El maestro y la maestra como asalariados}

A medida que el capital fue haciendo funcional la escuela a su proyecto, especialmente en el paradigma anglosajón del currículo, en donde la escuela fue organizada por la teoría de la administración de Taylor, el maestro dejó de ser apóstol y segundo padre o madre, y se fue convirtiendo a una serie de procesos que incluían una relación con el conocimiento, con las construcciones de la ciencia. Éstas, desde el modelo único de la ciencia basado en el positivismo (Sen y Kliksberg, 2007) y en la modelización de la física mecánica, con el acumulado de la pedagogía y de las ciencias sociales que interpretaban y explicaban el mundo, a la vez que dotaban de sentidos a la escuela. De igual manera, los procesos de su organización se veían sometidos a concepciones de administración fabril, las cuales generaban su ciclo a la supervisión e inspección.
La generalización del currículo americano (Tyler, 1992) trajo la idea de que él se convierta en el estructurador de la organización escolar. Después de la I Guerra Mundial, el paradigma sajón se hace hegemónico y la escuela va a construir una relación más clara de ella en función de un capitalismo que desde el mundo norteamericano se expandía en su nueva fase de mundialización (Wallerstein, 2011) con su correlato en educación a través del currículo.

A la luz de este control también surge la discusión sobre el sentido del trabajo docente en la sociedad, su lugar y significados para ese capital, que lo convertía en un asalariado con un grupo muy numeroso de sus representantes ejerciendo roles en el proceso de reproducción, la cual le reconoce su condición de trabajador y se comienza a organizar en sindicatos en la década del 60 y del 70 del siglo pasado, asumiendo esta forma a partir de la existencia de una relación laboral directa y con un patrón, abandonando las formas de colegios o asociaciones profesionales para colocar como central su condición de asalariado.

En esta perspectiva, la relación clásica, la escuela como lugar de trabajo guardando el símil de la fábrica, y el maestro el asalariado y trabajador de ella, es a partir de ese núcleo básico que se inician las relaboraciones sobre cómo entender al maestro y la maestra, y su lugar en la sociedad. Algunos sectores defienden esta postura colocando la centralidad en la condición de explotado y con matices discuten si ese trabajo es productivo directo (genera plusvalor) o indirecto (solo ayuda a la realización de la plusvalía). En ese sentido, es un trabajo necesario al capital. De esta matriz básica se comenzaron a escuchar replanteamientos que leen el papel del maestro y la maestra en la sociedad y que se desarrollan en la segunda mitad del siglo XX y lo corrido del presente.

Replanteamientos en la condición del maestro y la maestra

Un primer replanteamiento es el que reconoce que se da un cambio de la escuela inicial surgida en el paradigma francés a la luz de la Revolución Francesa (Plan Condorcet), que toma forma con el control sajón de ella, reelaborándola. El paradigma sajón, caracterizado 
por parcelar la escuela desde las disciplinas, luego influye en los paradigmas alemán y francés (Mejía, 2011) lo cual requiere otra organización del trabajo y otros medios para su realización, y es la necesidad de un trabajo pedagógico (más de los paradigmas europeos) que a su vez reordena e introduce las mediaciones técnicas y tecnológicas para poder hacer real su trabajo en la relación maestro(a)-estudiante, a través de dispositivos y didácticas.

Esta lectura abre los caminos interpretativos sobre el tipo de trabajo que realiza el maestro. Para unos es la consolidación de la proletarización clásica, ya que se realiza en condiciones de asalariado y en las cuales él no posee control sobre su trabajo, a semejanza de cualquier obrero, y los materiales son objetivación capitalista, en cuanto no depende de ellos, ya que es un trabajo totalmente racionalizado, y cada vez con una mayor determinación externa, que hace de él un trabajador que repite procesos productivos, señalados en planes, programas, competencias, estándares organizados desde afuera a través de textos de enseñanza y programas estandarizados.

Esta condición construye un maestro cada vez más dependiente de esas tecnologías educativas hechas desde afuera y que muestran el carácter de subordinado en la ruptura entre el trabajador y los medios de trabajo, que además le son enseñados como técnicas neutras, sin ideología, gestándose allí la alienación, bajo control de las regulaciones nacionales e internacionales de la educación. De allí la importancia de los mandos medios y el nuevo lugar del rector-gerente, quienes vigilan el cumplimiento de la patronización planificada.

A esta lectura se desarrolla otra, que compartiendo en lo básico el análisis, muestra cómo la asimilación de la escuela a la fábrica termina por construir al maestro, asimilado al obrero clásico y al buscar acomodar su quehacer a esas características de la teoría marxista clásica, pierde la perspectiva de análisis detallado desde las especificidades sobre la manera como se realiza el trabajo escolar, el cual si se analiza con detalles hace visibles elementos complejos más allá de la proletarización.
Las particularidades de un trabajo que por sus características tiene incorporados aspectos centrales de autonomía, que va a ser lo que le permite construir resistencias, dejando ver las fisuras de un sistema que al tener que otorgarle la centralidad a la escuela (en su sentido pleno, desde el jardín hasta el post-doctorado), por la manera como se hace central el trabajo inmaterial al capitalismo que reorganiza conocimiento, tecnología, información, comunicación, nuevos lenguajes, innovación e investigación para construir su proyecto de control, hace también muy visibles las grietas por donde emergen las resistencias y las formas de construir contrahegemonías, las cuales muestran y establecen particularidades y diferencias de estos dos tipos de trabajo en la sociedad (obrero fabril - maestro).

Aparece una primera diferencia en el trabajo del maestro y es que siendo trabajo asalariado, lo es de tipo inmaterial, con características y particularidades diferentes al trabajo material directo, y en ese sentido se señala cómo el trabajo propio del maestro debe ser leído por las características del nuevo proceso de acumulación basado en tecnología, conocimiento, innovación, investigación, información como un trabajo productivo, ya que ayuda a la valoración del capital, pues su resultado en el acto productivo es añadirle valor al capital, contribuyendo significativamente a su proceso de valorización, no siendo solamente actor del nivel de la circulación, en el sentido del numeral anterior de este texto.

Más allá de si es privado o público, dado que la función histórica del Estado ha sido asumir costos de aspectos necesarios para la realización de la ganancia del capital (seguridad social, vías, puertos, aeropuertos, educación y muchos otros), que luego entrega a los privados cuando éstos están en condición de que se genere plusvalor (Mejía, 2011). ¿Acaso no es el sentido profundo de lo público que se da actualmente en la confrontación con el neoliberalismo, al abdicar el Estado y entregarle al capital aquellos lugares en donde es posible que ellos los administren generando ganancias privadas?9

\footnotetext{
9 Desde sectores del neo-marxismo se propone recuperar las elaboraciones de Marx sobre el tipo de producción material e inmaterial, para construir desde allí la imbricación entre el trabajo capitalista y el trabajo pedagógico. Ya autores del Ilamado capitalismo cognitivo vienen reinstaurando la idea de "inteligencia general" en Marx para explicar el control y las nuevas luchas de estos tiempos.
} 
En esta perspectiva, se comienza a señalar que en esa diferenciación, el trabajo pedagógico no puede ser asimilado a las formas capitalistas del trabajo ampliadas y generalizadas del capitalismo industrial, sino que deben ser leídas desde su especificidad (Saviani, 1986) a la luz de la restructuración que el capitalismo hace de su proyecto frente a las nuevas realidades del trabajo inmaterial contenido en los procesos del conocimiento, la tecnología, la comunicación, la innovación y la investigación, en donde según la denominación de Marx, "la producción es inseparable del acto de producir", haciendo que producción y consumo sean inseparables en algunas profesiones, haciendo visible que las relaciones capitalistas son ilimitadas y se amplían apropiándose de los diferentes escenarios de la sociedad.

Es en el marco de esa concepción que desde diferentes lugares en América Latina y Europa se fundamenta el movimiento pedagógico como parte central de las luchas de un trabajador, que en su vinculación a él, como movimiento propio de esa subjetividad, muestra en la práctica esa especificidad en la cual el modo de producción capitalista tiene dificultades para generalizarse en el proceso de trabajo escolar, haciendo visibles las fisuras propias de éste tipo de práctica social, en cuanto genera espacios para desarrollar dinámicas y procesos de autonomía, más allá de las del asalariado fabril.

Este hecho permite en ese espacio de hegemonía y de reproducción que es la escuela, construir dinámicas como de contra-hegemonía y producción crítica generando procesos de resistencias múltiples y variadas, dando forma a propuestas en sentido diferente al orden capitalista, convirtiendo los espacios educativos, en sus múltiples ámbitos, en escenarios privilegiados de construcción de propuestas alternativas. Ello va a exigir un análisis del hecho educativo en una forma menos de reproducción y más abierto a las resistencias. De igual manera, va a exigir releer los sentidos del poder en un capitalismo globalizado y, en coherencia con ello, una elaboración especifica para la constitución en estos tiempos, de las concepciones y prácticas de emancipación y transformación ${ }^{10}$, muy visibles en las

10 Documento "Congreso social. Por un proyecto educativo". Santiago de Chile. 2012. (copia). diferentes luchas que hoy se dan contra la "naturalización" del proyecto neoliberal en educación.

En ese sentido, el control que se produce no es el mismo de la fábrica, en donde la inevitabilidad del proceso está marcada por una administración de tiempo, espacio, movimientos, donde el paso a paso construía el control sobre cuerpos y mentes. Allí mismo la fisura estaba marcada por una producción social que generaba y garantizaba la apropiación privada del plusvalor, a la vez que las condiciones para la organización obrera.

De esa manera, en la escuela hay la posibilidad de realizar el trabajo de una manera diferente a lo organizado por los manuales estandarizados propuestos en las últimas reformas y contrarreformas educativas de la globalización capitalista (estándares, competencias, formatos de calidad, entre otros). Es decir, hay la posibilidad de una elección para realizarlo de manera diferente, o hacer la tarea y desarrollar el quehacer en otra perspectiva, ya que el proceso escolar en el espacio concreto del territorio y el orden escolar lo organiza, lo prepara y lo ejecuta el maestro y la maestra desde la especificidad de los estudiantes con los cuales trabaja.

En esta perspectiva se hace real el sentido profundo de la desmaterialización de la producción, en cuanto forja una contradicción al capital, ya que por primera vez en la historia del control y el poder, el instrumento de trabajo es portado por el trabajador. Esto le permite a aquél, si tiene conciencia (tarea de las organizaciones), redirigirlo desde otros intereses y mostrar que esa manera de organizar la educación no es la única, de modo que asumiendo su condición desde una perspectiva alternativa, convierte su práctica pedagógica en un espacio de lucha. Allí muestra, en su quehacer, que el carácter político de la pedagogía no es externo a ella, no es otorgado por otros discursos, profesiones o ideologías, mostrando que la pedagogía es sustancialmente política, gestando allí no sólo resistencias, sino esas formas del trabajo en donde la producción y el consumo están ahí y no se pueden separar, es decir, son indisociables, abriendo las posibilidades de su manejo al actor de ellas, convirtiéndolas en uno de los lugares de construcción de los Proyectos Educativos y Pedagógicos Alternativos (PEPAs). 
Estas razones han llevado a que el capitalismo reestructure la función docente, buscando construirle regulaciones cada vez más estrictas para poder controlar este trabajo que no controla, y da origen a la disputa en la esfera de lo educativo y lo pedagógico desde la estructuración y organización de aspectos en donde se produce una tecnologización del proceso; por ejemplo, en la esfera de las nuevas tecnologías, la introducción de NTIC es un aspecto de ello. Así aparecen formas como la TV educativa, sistemas a distancia, instrucción con programación de computadores, entre otros ${ }^{11}$. También desde los libros aparecen con organización detallada instructivista, para hacer un control detallado del proceso educativo, y allí la pedagogía se convierte en central para construir la hegemonía y la contrahegemonía.

Esta situación se profundiza hoy con la reorganización de los procesos administrativos, que reestructuran contenidos y procedimientos del trabajo escolar, que buscan sacar del control del maestro y la maestra su quehacer. Un buen ejemplo de ello son las competencias y estándares, hechos por expertos por fuera de la escuela y colocados en la escuela para que sus actores los operacionalicen, mostrando otra vez ese control y también esa búsqueda de resistencias, concepción como en ejecución o los formatos que hay que Ilenar en los procesos de calidad, muchos de ellos en redes virtuales, para construir "la escuela eficiente".

Para evitar que emerja el saber del profesor, es ahí cuando el maestro y la maestra al mostrar la especificidad de su saber y su quehacer levanta como reivindicación redireccionar esos materiales planteados para fines específicos de control, desde su autonomía de su tiempo-espacio con otros intereses, para convertirse en transformador de la práctica y a través de ello producir saber sobre su quehacer, lo cual lo vincula a comunidades críticas y transformadoras.

Son estos elementos los que han ido constituyendo un acercamiento diferente a la concepción del maestro y pugnan por construir su estatuto, el cual busca ampliar su fundamento con nuevas bases. Ello exige mostrar cómo la naturaleza del trabajo docente se amplía con

11 Para una ampliación, remito a mi libro La(s) escuela(s) de la(s) globalización(es) II. Entre el uso técnico-instrumental y las educomunicaciones. Bogotá. Ediciones Desde Abajo. 2011. otras concepciones, abriendo otras perspectivas. Es reconocida la mirada de la pedagogía crítica norteamericana, insiste en esos elementos contradictorios y paradójicos del quehacer docente, que se dan en la tensión entre dominación-resistencia, que hace posible reconocer al maestro realizando un trabajo intelectual (Giroux, 1990) (propio del trabajo desmaterializado).

Esas especificidades hacen también del trabajo docente un sistema y entramado de relaciones sociales, que debe ser atendido en sus múltiples particularidades, que no son iguales a los de la clase obrera clásica. Ello exige no solo organización gremial y política en el sentido clásico del obrero fabril, sino en la capacidad de colocar en un horizonte organizativo esas múltiples diferencias, dándole forma a ellas en la vida de la organización, convirtiendo al asociado en un asalariado que es atendido en esas múltiples posibilidades, más allá del gremialismo reducido a lo económico, que se abren al releer su condición por quienes le proponen representar sus intereses con esas múltiples facetas que muestran su naturaleza e identidad en estos tiempos.

Es en esa lógica que comienza a encontrarse esos elementos que constituyen esa condición, la de ser maestro y maestra en este tiempo, en este tipo de capitalismo con sus nuevas formas de control y poder, sobre todo, dando forma a sus particularidades de clase, las cuales deben ser comprendidas y organizadas con nuevas propuestas, complementando las tradicionales, lo cual da también lugar a las transformaciones de la organización gremial que los representa.

Es así como en el marxismo sajón se cuestiona esa mirada maximalista, que niega especificidades, haciendo que la lógica del capital y su racionalización sea homogénea en toda la sociedad y en alguna medida, el reconocimiento de cómo estas lecturas estructurales y deterministas no reconocen el carácter histórico de las clases y las particularidades de su quehacer y los contextos y las especificidades diferenciadas que toman los diferentes sujetos como actores particulares que toman en algunos sectores, construyendo dinámicas de resistencia para enfrentarlas formas del control y el poder.

Algunos plantean la necesidad de un puente conceptual que permita relaborar lo humano y la teoría del trabajo 
en el capitalismo actual, que presenta diferencias a la constitución de éste en los tiempos iniciales de la profesión de maestra y maestro, en el cual sin abandonar la cuestión de clase, debe darse cuenta de las nuevas relaciones sociales escolares, comunitarias y culturales que se gestan en las nuevas condiciones (Lawn, 1987).

También frente a las teorías de la proletarización y descualificación, algunos procesos muestran que en el pasado esto fue más controlado. En estos momentos se asiste también a procesos de recalificación y en su autonomía relativa se producen contrapropuestas a la racionalización (Lawn y Ozga, 1988), y algunos de los emergentes espacios de formación se realiza ante la llegada de nuevos campos del conocimiento y la necesidad de la innovación, para dar respuesta a las transformaciones epocales y la modernización capitalista, lo cual construye un campo en disputa propio del quehacer docente, más allá de una racionalización a ultranza de control y dominio de la forma fabril, lo cual implica trabajar esas diferencias para construir con especificidad las luchas y sentidos del magisterio actual.

Un caso interesante es poder reconocer cómo al perfilarse el lugar del maestro y la maestra en la sociedad actual como trabajadores necesarios para la cualificación y constitución del trabajo inmaterial, va a requerir de procesos de formación específicos y diferenciados para poder responder a los nuevos requerimientos a través de campos de saber y conocimiento. De igual manera, todo el campo de la tecnología introduce la necesidad de una reflexión sobre los lenguajes, en especial el digital, y la cultura y el mundo virtual que se crea, construyendo unas nuevas realidades que no pueden ser interpretadas en la sola lógica de dominación, ya que abre múltiples caminos de cualificación y contrahegemonía, exigiendo una reflexión para ese uso diferenciado, lo que también abre múltiples posibilidades de introducir procedimientos y técnicas nuevas, haciendo visible la emergencia de una proletarización técnica y la posibilidad de desplegar sus capacidades humanas y contrarrestar la manera como se regula el control de éstos desde las competencias y los estándares.

Muchos de los estudios pioneros de corte etnográfico, que en el caso colombiano han sido soporte del movimiento pedagógico (Tezzanos, 1984) y otras experien- cias que visibilizan esa otra condición del maestro y la maestra, leídas desde su quehacer cotidiano, muestran cómo la actividad de los sujetos en la acción educativa es muy diferente al mundo fabril, las posibilidades de comportarse como actores del proceso y donde desarroIlan formas diferentes, contrahegemónicas, en muchos casos con producciones propias de resistencia, a lo que se les propone desde las entidades reguladoras de educación, es un buen ejemplo de ello. La experiencia de la Expedición Pedagógica Nacional muestra ese maestro que convierte el proceso de control en lugar de creación e impugnación haciéndose productor de saber y conocimiento, creador de geopedagogías (Quiceno y Messina, 2000).

Sus libros publicados, así como los videos, son testimonio y hacen visible lo enunciado acá y muestran la manera como es vivida esa resistencia, como acto creador que los convierte en productores de saber de impugnación ${ }^{12}$, visibilizando que eso es muy diferente del fordismo y el taylorismo, en la fábrica y en la escuela. Allí emergen esos intersticios y fisuras donde se construye ya la contrahegemonía, y ello va a requerir de una nueva alianza escuela-gremio-academia, dando forma a una escuela pública de excelencia, que es una responsabilidad de toda la sociedad y su propuesta una alianza de los trabajadores del trabajo inmaterial en el capitalismo de estos tiempos para poder profundizar esos elementos, así como a la organización del magisterio para encauzar esos escenarios en un horizonte

12 UNIVERSIDAD PEDAGÓGICA NACIONAL. (2001). Expedición Pedagógica No. 1: Huellas y registros. Bogotá. Bogotá, D. C. Universidad Pedagógica Nacional.

(2001). Expedición Pedagógica No. 2: Preparando el equipaje. Bogotá, D. C. Universidad Pedagógica Nacional.

- (2003). Expedición Pedagógica No. 4: Caminantes y Caminos. Expedición Pedagógica en Bogotá. Bogotá, D. C. Universidad Pedagógica, Fundación Restrepo Barco.

(2005). Expedición Pedagógica No. 6: Con los dedos en la filigrana. Una lectura crítica a los tejidos metodológicos de la Expedición Pedagógica Nacional. Bogotá, D. C. Universidad Pedagógica Nacional - Fundación Restrepo-Barco.

-------- (2005). Expedición Pedagógica No.7: Recreando rutas y senderos pedagógicos en Valle, Cali y región norte del Cauca. Bogotá, D. C. Universidad Pedagógica Nacional - Universidad del Valle.

(2005). Expedición Pedagógica No. 9: Rutas de vida, maestros, escuelas y pedagogía en el Caribe colombiano. Bogotá, D. C. Universidad Pedagógica Nacional - Red pedagógica del Caribe. 
emancipador, recreando la organización para darle cabida a esos múltiples procesos que constituyen los eslabones de los proyectos educativos y pedagógicos alternativos (PEPAs).

De igual manera, la experiencia de Paulo Freire como Secretario de Educación de la ciudad de São Paulo y su posterior reflexión sobre la autonomía del maestro y la maestra (Freire, 1996) muestra cómo en la escuela las relaciones sociales toman forma educativa y escolar, haciendo de la pedagogía un escenario de concreción de las apuestas políticas de los maestros y las maestras (político-pedagógicas). En este caso, muestra que sí se tiene una propuesta ético-política, caben procesos concientizadores desde la determinación y apuesta de sus actores para realizarlo, y que muestra cómo la escuela no es una institución de control totalmente subordinada y sin posibilidades de resistencia, convirtiendo a la escuela en un escenario de confrontación de las diferentes visiones que quiere dirigir la sociedad, pero con especificidades educativas y pedagógicas, haciendo de ello una institución contradictoria y en disputa.

En esta perspectiva, el nuevo discurso modernizador de la escuela que viene realizando el proyecto de control de estos tiempos, ha convocado a sus mejores pensadores para realizarlo y requiere un ejercicio igual de riguroso para buscar caminos alternativos y elaborar propuestas para su realización en el cotidiano de la institucionalidad educativa. De igual manera, seguir con detalle sus debates, lo cual muestra el conflicto de la hegemonía para su realización, lo cual nos permite reconocer esos aspectos a profundizar y exigir mostrar caminos alternativos ( Ravitch, Octubre 2010).

Asimismo, en la experiencia del movimiento pedagógico colombiano, se hacen visibles las voces que retomando el pensamiento de Antonio Gramsci plantean la escuela como un lugar de contra-hegemonía cultural (Gantiva, 2007), donde el maestro consciente de ello se convierte en un intelectual orgánico que se pone al servicio de la construcción de contrahegemonía, en la especificidad del trabajo pedagógico y educativo, dando forma a lo que Giroux denominaría luego el intelectual de frontera y transformador13(Giroux, ) propiciado por

13 Giroux, H. Teoría crítica y resistencia en educación. la variedad de grupos que se constituyen en el ejercicio cotidiano de la actividad escolar y que retoman pensamiento del acumulado de los proyectos emancipadores en la cultura y convierten la pedagogía en un asunto central y fundamentalmente político (Torres, 2008). Ello visibiliza las contradicciones del capitalismo en las formas que toma la educación y la escuela en su concreción, lo cual permite unas autonomías relativas a través de las cuales circula la lucha y las búsquedas alternativas, las cuales hoy van tomando forma en un movimiento pedagógico más allá de lo gremial, el cual se expresa en la búsqueda de proyectos educativos y pedagógicos alternativos (PEPAs) en diferentes ámbitos de movimientos, grupos y personas de la sociedad que se plantean en la esfera de la emancipación.

En Colombia, algunas de estas expresiones han tomado forma en las experiencias de transformación pedagógica, quienes cuestionando la idea de innovación entendida como experiencia exitosa, colocándola en un horizonte transformador, muestran cómo al reconocer su actoría social se convierten en actores que modifican su quehacer y se hacen creadores y transformadores, y cuando avanzan construyendo comunidades, dan forma a coordinaciones, las cuales muestran la potencia de un maestro que enfrenta la dominación desde sus prácticas cotidianas, la expresión de la escuela de Filodehambre ${ }^{14}$ y las de educación propia del Consejo Regional Indígena del Cauca (CRIC) y las más de 3,000 visibilizadas por la Expedición Pedagógica, y muchas otras que nos haríamos largo enumerar, nos hacen visible cómo la sobredeterminación del capital y el poder no es absoluta, y la capacidad humana (cognitiva, afectiva, valorativa y volitiva) de hacer de la innovación un proyecto de transformación es total si existe la formación para ello, lo cual requiere de los actores colectivos organizados, capaces de recoger esa infinidad de experiencias y darles sentido de comunidad de práctica, aprendizaje, saber, conocimiento y transformación 15 , construyéndolas a la luz de las nuevas realidades del trabajo inmaterial.

14 Colectivo de Educadores. (1987).Filodehambre: una experiencia popular de innovación educativa. Neiva, Huila, Colombia. Escuela Popular Claretiana.

15 Programa de Educación Bilingüe e Intercultural PEBI-CRIC. (2004) ¿Qué pasaría si la escuela ? 30 años de una educación propia. Popayán. Consejo Regional Indígena del Cauca. 
Damos la palabra al maestro Fals-Borda, quien en uno de sus últimos eventos trazaba la tarea:

"El énfasis en el papel de los contextos culturales, sociales y ambientales puede ayudar a enfocar desde una nueva perspectiva, el tema de los paradigmas científicos que, en opinión de muchos, sigue siendo el próximo paso con la IAP. Éste es un reto para el cual contamos, de manera preliminar, con los presupuestos de la praxología, los de los filósofos postmodernos, citados atrás, y los resultados de las convergencias interdisciplinarias planteadas.

Al tomar el contexto como referencia y a los conceptos teóricos de praxis con frónesis, descubrimos una veta casi virgen de ricos conocimientos de las realidades de nuestros pueblos autóctonos, de nuestras raíces más profundas, por fortuna todavía vivas. Recordemos que los paradigmas que han moldeado nuestra formación profesional, en general, han sido constructos socioculturales de origen eurocéntrico. Ahora tratamos de inspirarnos en nuestro propio contexto y dar a nuestros trabajos el sabor y la consistencia propias del tercer mundo y su trópico, con un paradigma más flexible, de naturaleza holística y esencia participativa democrática. Para llegar a estas metas, la arrogancia académica es un serio obstáculo, debía archivarse.

Hace tres siglos, Juan Bautista Vico delimitó con su crítico bisturí una "ciencia nueva" para un "nuevo orbe". Como el mismo autor lo previó, aquel reto se ha adelantado con dudosos resultados. Hoy hay un desafío paralelo para desarrollar una nueva ciencia responsable, democrática y participante, para arreglar un mundo sobre-explotado y envejecido, en crisis, con amenazas de descomposición desde los cielos hasta las cavernas". ${ }^{16}$

\section{Referencias}

Ramonet, I. (1997). Un mundo sin rumbo. Madrid. Debate.

Rifkin, J. (2000). La era del acceso. La revolución de la nueva economía. Buenos Aires. Paidós.

Amin, S. (2001). Crítica de nuestro tiempo. A los 150 años del Manifiesto Comunista. México. Siglo XXI.

Virno, P. (2003). Gramática de la multitud. Madrid. Traficante de sueños.

Sassen, S. (2001). ¿Perdiendo el control? La soberanía en la era de la globalización. Barcelona. Bellaterra.

Offe, C. \& Hinrichs, K. (1992). La sociedad del trabajo. Problemas estructurales y perspectivas de futuro. Madrid. Alianza.

Tronti, M. (1999). Obreros y capital. Madrid. Akal.

Santos, S. (2009). Una Epistemología del Sur. La reinvención del conocimiento y la emancipación social. Buenos Aires. Siglo XXI Editores. CLACSO.

16 FALS-BORDA, O. La Investigación Acción en convergencias disciplinarias. Conferencia para recibir el premio Malinowsky de la Society for Applied Anthropology y el premio Oxfam-América Martin Diskin de la Latin American Studies Association (LASA). Borrador (3). Agosto de 2007.
Martin-Barbero, J. (2007). "¿Razón técnica vs. razón pedagógica?", en: Zuleta, M.; Cubides, H. y Escobar, M. R. (Editores). ¿Uno solo o varios mundos? Diferencia, subjetividad y conocimientos en las ciencias sociales contemporáneas, P. 215. Bogotá, Universidad Central - IESCO. Siglo del Hombre Editores.

Rubin, I. L. (1974). Ensayos sobre la teoría marxista del valor. Buenos Aires. Cuadernos de Pasado y Presente.

Mandel, E. (1997). Tratado de economía Marxista. México. Editorial Era.

Braverman, H. (1984). Trabajo y capital monopolista: la degradación del trabajo en el siglo XX. México, DF. Nuestro Tiempo.

Sen, A. y Kliksberg, B. (2007). Primero la gente. Una mirada desde la ética del desarrollo a los principales problemas del mundo globalizado. Barcelona. Deusto.

Tyler, R. (1992). Principios básicos del curriculum. Buenos Aires. Ediciones Troquel.

Wallerstein, I. (2011). The Modern World-System IV: Centrist Liberalism Triumphant, 1789-1914, California, University of California Press.

Mejía, M. R. (2011). Educaciones y pedagogías críticas desde el Sur. Cartografías de la Educación Popular. Bogotá. Editorial Magisterio.

Mejía, M. R. (2011). (2011). "Lo público: una construcción de poderes en conflicto con formas propias en lo educativo (borrador en construcción)". Documento elaborado para la Escuela de Formación Sindical de FECODE, en el módulo de Derechos Económicos, Sociales y Culturales. Inédito.

Saviani, D. (1986). Ensino público e algumas falas sobre a universidade. $3^{\text {a }}$ Ed. São Paulo. Cortez.

Giroux, H. (1990). Los profesores como intelectuales. Barcelona. Paidós.

Lawn, M. (1987). Servants of the State: The Contested Control of Teaching 1900-1930. London. Falmer Press.

Lawn, M. y Ozga, J. (1988). “¿Trabajador de la enseñanza? Nueva valoración de los profesores". En: Revista de Educación, Núm. 285, enero-abril. Madrid. 1988. Págs. 191-215.

Tezzanos, A. (1984). "Por qué un movimiento pedagógico" En: Educación y cultura. Revista del Centro de Estudios e Investigaciones Docentes - CEID, de la Federación Colombiana de Educadores. No.1, julio de 1984. Bogotá.

Quiceno, H. y Messina, G. (2000). Expedición a la Expedición Pedagógica Nacional. Bogotá. Universidad Pedagógica NacionalFundación Restrepo-Barco.

Freire, P. (1996). Pedagogia da autonomia. Saberes necessários à prática educativa. São Paulo. Paz e Terra.

Ravitch, D. (Octubre 2010). Le Monde Diplomatique "El Diplo" Edición Colombiana. Volumen 8, No.94. "¿Qué hacer con la educación secundaria? Por qué cambié de opinión." Páginas 4-5.

Gantiva, J. (2007). Un ensayo sobre Gramsci. El sentido de la filosofía en la política y la tarea de pensar. Caracas. Centro Internacional Miranda.

Torres, A. (2008). La educación popular. Trayectoria y actualidad. Bogotá. Editorial El Búho. 